Article

\title{
Promoting Social Inclusion through Sport for Refugee-Background Youth in Australia: Analysing Different Participation Models
}

\author{
Karen Block * and Lisa Gibbs \\ Centre for Health Equity, Melbourne School of Population and Global Health, University of Melbourne, Melbourne, VIC 3010, \\ Australia; E-Mails: keblock@unimelb.edu.au (K.B.), I.gibbs@unimelb.edu.au (L.G.) \\ * Corresponding author
}

Submitted: 3 February 2017 | Accepted: 6 April 2017 | Published: 29 June 2017

\begin{abstract}
Sports participation can confer a range of physical and psychosocial benefits and, for refugee and migrant youth, may even act as a critical mediator for achieving positive settlement and engaging meaningfully in Australian society. This group has low participation rates however, with identified barriers including costs; discrimination and a lack of cultural sensitivity in sporting environments; lack of knowledge of mainstream sports services on the part of refugee-background settlers; inadequate access to transport; culturally determined gender norms; and family attitudes. Organisations in various sectors have devised programs and strategies for addressing these participation barriers. In many cases however, these responses appear to be ad hoc and under-theorised. This article reports findings from a qualitative exploratory study conducted in a range of settings to examine the benefits, challenges and shortcomings associated with different participation models. Interview participants were drawn from non-government organisations, local governments, schools, and sports clubs. Three distinct models of participation were identified, including short term programs for refugee-background children; ongoing programs for refugee-background children and youth; and integration into mainstream clubs. These models are discussed in terms of their relative challenges and benefits and their capacity to promote sustainable engagement and social inclusion for this population group.
\end{abstract}

\section{Keywords}

integration; migrant; participation; refugee; social inclusion; sport; youth

Issue

This article is part of the issue "Sport for Social Inclusion: Questioning Policy, Practice and Research", edited by Reinhard Haudenhuyse (Vrije Universiteit Brussel, Belgium).

(C) 2017 by the authors; licensee Cogitatio (Lisbon, Portugal). This article is licensed under a Creative Commons Attribution 4.0 International License (CC BY).

\section{Introduction}

Each year, Australia settles approximately 13,500 people on humanitarian visas, with recent temporary increases to these numbers announced to accommodate more refugees fleeing conflict in Syria. While the source countries for refugee-background migrants to Australia vary from year to year, in the two years from July 2014 to June 2016 the top five countries of origin were Iraq, Syria, Burma, Afghanistan and the Democratic Republic of Congo and the intake included just over 10,500 young people under the age of 18 (Australian Department of Immigration and Border Protection, 2017). More than a quarter of the total settled in the state of Victoria with the majority in Melbourne, where this research was conducted (CMY, 2016).

Sports participation can offer a range of physical and psychosocial benefits likely to foster health, wellbeing and social inclusion (Eime, Young, Harvey, Charity, \& Payne, 2013). This potential has resulted in sport being seen as an important instrument in social policy with the capacity to promote not only physical and mental health but also to reduce youth antisocial behaviour, improve community cohesion and safety, and reduce health inequalities (Hoye, Nicholson, \& Brown, 2015; Vermeulen \& Verweel, 2009). It may also assist re- 
cently arrived young people with language acquisition, self-esteem, confidence and social connectedness. Participation by refugee-background migrants in community clubs can play an important role in fostering a sense of community belonging (SCOA, 2012; Spaaij, 2012), perhaps particularly so in Australia given the popularity and pervasiveness of sport within Australian culture (Refugee Council of Australia, 2010).

The potential benefits are particularly salient for disadvantaged and marginalised young people at risk of poor educational, health and social outcomes associated with social exclusion. Risk factors for exclusion commonly experienced by refugee-background young people include residing in disadvantaged neighbourhoods, disrupted education prior to arrival in Australia, poverty, discrimination, trauma-associated mental and physical health problems, and living in families torn apart by war and violence and struggling with multiple settlement challenges. This group has low participation rates however, with identified barriers that include costs; lack of access to transport; a lack of cultural sensitivity in sporting environments; a lack of knowledge of mainstream sports services on the part of refugee-background settlers; culturally determined gender norms; competing settlement priorities; and family attitudes (Caperchione, Kolt, \& Mummery, 2009; O'Driscoll, Banting, Borkoles, Eime, \& Polman, 2013; Olliff, 2007; Rosso \& McGrath, 2013; Spaaij, 2013). A report by Oliff (2007) on the potential role of sport and recreation as an aid to integration of refugee young people argues that targeted programs can facilitate settlement, promote health and wellbeing and be an entry point to broader participation and social inclusion.

There is however, a dearth of robust evidence to either support or disprove many of the benefits intuitively attributed to sports participation. A systematic review has identified a lack of research into participation by culturally and linguistically diverse migrants as a key gap in the literature (Kay, 2009; O'Driscoll et al., 2013). Moreover, sports interventions and programs targeting refugee-background young people frequently lack a clear theoretical rationale and are often short-term, ad hoc and difficult to sustain (Refugee Council of Australia, 2010). Several researchers have emphasised that the capacity of sport to promote social inclusion is limited and shaped by broader social and structural exclusionary processes rendering the social impacts of sport highly contextually dependent (Coalter, 2015; Hoye et al., 2015; Kelly, 2011; Spaaij, Farquharson, \& Marjoribanks, 2015). Theoretically informed investigations are therefore needed that take into account factors such as cultural and social diversity, gender and local processes of inclusion and exclusion.

This article reports findings from an exploratory qualitative study that examined the variety of sports participation models available to young people from refugee backgrounds in Melbourne, Australia. The project aimed to clarify the underlying assumptions and implicit concep- tual frameworks supporting different participation models and examine the respective benefits, challenges and shortcomings of each from the perspectives of those providing the programs. Three distinct models of participation were identified, including short term programs for refugee-background children; continuing programs for refugee-background children and youth; and integration into mainstream clubs. These models are discussed in terms of their impacts and their capacity to promote sustainable engagement and social inclusion for this population group.

\section{Theoretical Frameworks: Social Inclusion and Social Capital}

Optimistic views of the social impact of sports participation often focus on its potential to build social capital (Coalter, 2007; Hoye et al., 2015). Social capital can broadly be defined as 'a range of thinking around norms and networks; the values and resources that both result in, and are the product of, socially negotiated ties and relationships' (Cheong, Edwards, Goulbourne, \& Solomos, 2007, p. 25). This broad definition encompasses the two most common, yet distinct, ways in which social capital is conceptualised-as either an individual or a collective asset. Network conceptions of social capital (based on the work of Bourdieu, 1986) focus on resources that flow differentially through personal networks to individuals, whilst communitarian conceptions (based on Putnam, 2000) are concerned with positive social norms, created by community level connectivity and available to all (Hawe \& Shiell, 2000). Both are likely to be important for facilitating social inclusion.

Distinctions are also made between bonding social capital, drawn from networks where there is a shared identity such as between family and close friends, and bridging social capital, which refers to informal or formal groupings that cut across 'ethnic, gender, caste, class, wealth, religion, location or any other characteristics which distinguish social groups' (Narayan, 1999, p. 7). Linking social capital can be conceptualised as a variant of bridging capital comprising connections between individuals and institutions (Woolcock, 2001). These distinctions are particularly relevant when considering the capacity of social capital to promote broader social inclusion for refugee-background young people. While there is general agreement in the literature that social connections and networks are vital components of refugee inclusion and wellbeing, there is less agreement over the assigned value of different types of social capital. Some authors emphasise the importance of both bonding and bridging ties. Others note the limitations and potential negative effects of exclusive reliance on bonding ties for migrants, arguing that strong ties within disadvantaged communities can contibute to exclusion (Eriksson, 2011; Wakefield \& Poland, 2005). Many scholars correspondingly stress the value of bridging capital for providing additional resources to such communities (Ager \& Strang, 
2008; Beirens, Hughes, Hek, \& Spicer, 2007; Field, 2003; Hardwick, 2003; Korac, 2003).

A conceptual framework for understanding domains of social integration has been developed by Ager and Strang (2008). The model is based on research with refugee background settlers in the UK and proposes ten domains of inclusion. While the authors of this framework refer to integration (rather than inclusion) the framework effectively captures the multidimensional and interactive nature of domains that constitute social inclusion or exclusion. Education, employment, housing and health are described as both 'markers' and 'means' of integration. Having access to these domains both represents the state of inclusion and the means for bringing it about. The model explicitly incorporates theories of social capital by positioning bonding, bridging and linking connections as key mediators of inclusion. Facilitators of integration comprise social capabilities represented by language and cultural knowledge; and having a sense of safety and stability. All of these domains rest on a foundational domain of rights and citizenship. The model thus draws together a number of theoretical and conceptual frameworks-including social inclusion, social capital and human rights-and emphasises the codependence and links between domains.

The diagram (Figure 1) below depicts Ager and Strang's (2008) framework. Based on the evidence cited earlier in this paper, we would expect that a range of these domains-including social connections, facilitators and markers and means-have the potential to be enhanced by sports participation.

Building on this model, Spaaij (2012) has suggested that recreational sport may be viewed as an additional marker and means of integration. The following discus- sion uses this conceptual model and embedded theories concerning social capital to discuss the conditions and contexts through which sports participation may contribute to integration and inclusion.

\section{Method}

A qualitative exploratory study was conducted in a range of settings offering sporting activities for recently arrived young people in Melbourne, Australia. Ethics approval for the project was obtained from the University of Melbourne Human Research Ethics Committee and data collection took place between June and December 2014.

Interview participants for this research were drawn from non-government organisations, local governments, schools, and sports clubs-including elite clubs providing outreach programs and grassroots clubs attempting to integrate refugee-background young people into their teams. Potential participants were identified through discussions between the researcher and representatives of relevant organisations such as sports governing bodies, local councils, community clubs and schools in areas with significant numbers of refugee-background settlers. A purposive sampling strategy was used to select participants representing programs and settings that provided a range in terms of sports being undertaken; age and gender of participants; school and community-based programs; and program models.

Interviews were semi-structured to allow unanticipated as well as anticipated themes to emerge. They were conducted at a time and place convenient to the interviewee and lasted an average of 60 minutes with a range of 30 to 90 minutes. Interview prompts focused on elucidating the objectives (and implicit or explicit theo-

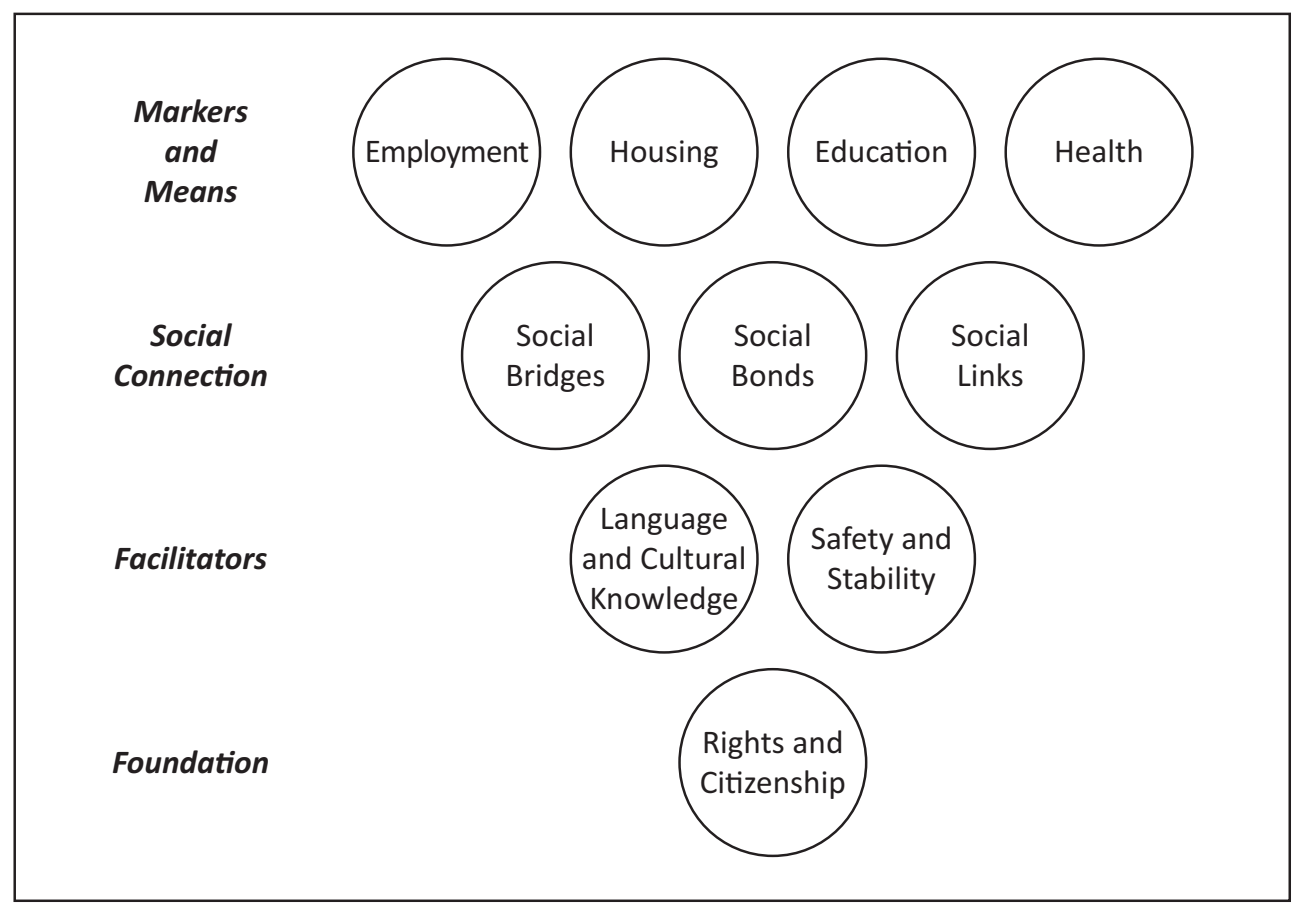

Figure 1. A conceptual framework defining core domains of integration (Ager \& Strang, 2008). 
retical underpinnings) of programs and their consequent capacity to promote inclusion; identifying contextual and other factors (barriers and facilitators) leading to successful (or unsuccessful) and sustainable (or unsustainable) attempts to include refugee young people in sports; and identifying key features of high quality practice within schools and community settings to inform development of future interventions.

Interviews were recorded and transcribed verbatim with NVivo 11 (QSR International, 2015) used as a data management tool. Transcripts were analysed using inductive and abductive qualitative methods, examining the data for patterns and themes and using existing theoretical frameworks as sensitising concepts against which emergent themes were continually tested (Charmaz, 2003).

\section{Participants}

Ten participants (three female and seven male) took part in interviews. Their organisation type, roles, sports and participation models covered by each are summarised in Table 1 below. All participants had roles that were specifically focused on facilitating sports participation (primarily in team sports) by refugee background migrants and they included representatives from NGOs providing settlement support and sports programs, grassroots and elite clubs, schools and local government. A number of interviewees oversaw or had a role in promoting more than one model of participation while others were involved in promoting a single model. The three distinct models that were identified-short term programs or events; continuing programs for refugee-background children and youth; and integration into mainstream clubs were fairly evenly represented across the project.

\section{Perceived Benefits Associated with Each Participation Model}

Interview participants were generally enthusiastic about each of the participation models in which they were involved and felt that sport was an effective way to connect with young people and influence their behaviours and values.

Table 1. Summary of interview participant characteristics.

\begin{tabular}{|c|c|c|c|c|c|c|}
\hline \multirow[t]{2}{*}{ Participant } & \multirow[t]{2}{*}{ Type of organisation } & \multirow[t]{2}{*}{ Position/Role } & \multirow[t]{2}{*}{ Sports } & \multicolumn{3}{|c|}{ Participation models* } \\
\hline & & & & 1 & 2 & 3 \\
\hline 1 & $\begin{array}{l}\text { NGO providing } \\
\text { settlement support }\end{array}$ & Program coordinator & $\begin{array}{l}\text { All sports-especially } \\
\text { football (soccer) and } \\
\text { basketball }\end{array}$ & $x$ & $x$ & \\
\hline 2 & Grassroots sports club & $\begin{array}{l}\text { Multicultural liaison } \\
\text { worker }\end{array}$ & Basketball & & & $x$ \\
\hline 3 & $\begin{array}{l}\text { Primary school with large } \\
\text { numbers of refugee- } \\
\text { background families. }\end{array}$ & $\begin{array}{l}\text { Community and family } \\
\text { engagement }\end{array}$ & $\begin{array}{l}\text { All sports-especially } \\
\text { football (soccer) }\end{array}$ & $x$ & & \\
\hline 4 & $\begin{array}{l}\text { NGO providing sports } \\
\text { program }\end{array}$ & Executive Director & Basketball & & $x$ & \\
\hline 5 & $\begin{array}{l}\text { Primary school with } \\
\text { large numbers of } \\
\text { refugee-background families } \\
\text { and grassroots sports club }\end{array}$ & $\begin{array}{l}\text { Assistant principal of } \\
\text { school and senior coach } \\
\text { at sports club }\end{array}$ & $\begin{array}{l}\text { All sports-especially } \\
\text { cricket }\end{array}$ & & $x$ & $x$ \\
\hline 6 & Elite sports club & $\begin{array}{l}\text { Community and } \\
\text { diversity manager }\end{array}$ & $\begin{array}{l}\text { Australian rules } \\
\text { football (AFL) }\end{array}$ & $x$ & & \\
\hline 7 & Local government & $\begin{array}{l}\text { Sport and recreation } \\
\text { development officer }\end{array}$ & $\begin{array}{l}\text { All sports-especially } \\
\text { football (soccer) }\end{array}$ & $x$ & $x$ & $x$ \\
\hline 8 & $\begin{array}{l}\text { NGO providing sports } \\
\text { program }\end{array}$ & Chair of the board & All sports & $x$ & & $x$ \\
\hline 9 & Grassroots sports club & $\begin{array}{l}\text { Volunteer committee } \\
\text { member }\end{array}$ & Football (soccer) & & & $x$ \\
\hline 10 & $\begin{array}{l}\text { NGO providing sports } \\
\text { program }\end{array}$ & General manager & All sports & $x$ & & $x$ \\
\hline
\end{tabular}

Note: ${ }^{*} 1$ = Short term programs and events, 2 = Continuing school or community-based programs, 3 = Supporting integration into mainstream clubs. 
Discussing short term sports activities run in her primary school, Participant 3 explained how she valued the connections developed between children and adults and amongst the children themselves.

Those programs, they're short and they're fun! So fun. I like the fact that they are exposed to adults having fun with them. I know, as a parent, when was the last time I played kick to kick? Certainly these parents don't....These adults act in a different way to teachers and a different way to parents, so that is probably the number one thing...

I was there for that first cross country where all the kids were training and it was amazing! Looking at those kids and the way they supported each other and the way that they cheered each other on... that was really what it was about, getting to the end of it. (Participant 3)

A continuing program based in a secondary school was seen as having similarly positive outcomes.

The school said that the one thing, the one positive in their lives is soccer....These group of boys that all we hear is they're trouble, they're this, they're that. When they're playing soccer they're perfect. Focused, teamwork-it's incredible. The power of the passion....It's exciting to be on a program that kids respond to. A lot of youth work it's like " $m e h$ ", but when kids respond so positively to it it's just a joy to work on it! (Participant 1)

The third participation model, integration into mainstream clubs, also received glowing reports. Despite being warned by a youth worker who referred some of the young people to the club that 'there might be behaviour problems', a volunteer committee member reported:

The kids were so pleased to join a club and be able to play. That's what they really wanted. Really super enthusiastic to get to training, very enthusiastic at training and wanted to do everything. Very easy to get along with, listened to instructions, got on well with the other kids. (Participant 9)

\subsection{Markers and Means of Inclusion: Health, Wellbeing and Education}

Interviewees representing each of the different participation models saw associated benefits in terms of health and wellbeing. A number of participants emphasised the physical health benefits associated with being fit and active. More commonly however, they spoke about benefits contributing to mental health and wellbeing such as self-esteem, positive self-image, goal setting and leadership skills. Providing an opportunity for young people to experience success and a sense of achieve- ment was seen as an important outcome by many of those interviewed.

For a lot of our refugee population the kids are struggling at school. They're finding school quite difficult and then they'll get involved in sport and they're actually pretty good at sport. It's their own self-efficacy and just to be able to have something that they're really good at and they can achieve well. I think it does wonders for the way they view themselves in the world. (Participant 5)

We're going to get [the year 9 boys] to develop a sport skills building program that they can deliver to primary schools and then that kind of builds their confidence up and it shows off the skills that they've learned (Participant 1)

Similarly, each of the participation models was regarded by participants as having flow on benefits for education. Several interviewees felt that values and interpersonal skills developed through participation in sport were transferable to the classroom. Participant 1 coordinated a 'soccer scholarship program' which offered weekly lunchtime and after-school coaching sessions to refugee-background students regarded as being at high risk of disengagement. It was anticipated that the program would help to keep these young people at school and it also used rewards such as new soccer boots to encourage improved classroom behaviour.

Participant 5, who was both an assistant principal at a school and a sports coach saw distinct educational benefits associated with young people's participation in sport. He spoke about them learning to apply values and skills that they learned from playing sport such as 'working hard', 'persistence' and 'bouncing back from disappointment' to other aspects of their lives including their education. He also described ways in which he was able to use some of the boys' enthusiasm for cricket in the classroom.

Some of my Grade 5/6 boys who are really into their cricket will do stuff around maths...lots and lots of maths with the scoring... (Participant 5)

Several of the participants were also involved in linking sports programs to mentoring programs that offered educational and social support to students. An interview participant representing an elite Australian Rules Football club discussed a partnership the club had formed with a local primary school in which they ran short term sports programs in the school and also mentored refugee background children. He saw tremendous value in the positive male role models offered to the children, many of whom had no father at home, and offered the following anecdote:

Then there's also a literacy program which we've just launched...it started with the idea of having us read- 
ing in front of the class...to become socially acceptable amongst the kids for boys to read books. So apparently the next day the library was sort of emptied which is [amazing]! (Participant 6)

Two of the interview participants had supported refugeebackground young people who had gone on to receive basketball scholarships to colleges in the United States.

\subsection{Social Connections}

All interview participants spoke about the impacts of sports participation on social relationships and connections. Participation in enjoyable group activities-even short term or one-off events was seen as strengthening bonding connections and sometimes also linking connections. Three different participants mentioned, for example, how Victoria Police had engaged in their sport programs to strengthen relationships with refugeebackground communities.

Both short term and continuing programs were also explicitly used by interviewees and their organisations to build an array of linking connections between community organisations and institutions and refugeebackground young people. Participant 1 , described how her organisation used sport to link participants into other youth supports.

You probably know - traditionally refugee and CALD [culturally and linguistically diverse] kids don't go to generalist youth services and across the board...local youth services find it hard to engage with these kids....We use [sport] in a lot of our programs as a tool of engagement...we feed the boys, bring them down, have soccer, and talk about what's going on....So sports is great because kids open up. They're running around kicking a ball, they sit down for a break, you sit down beside them. It's perfect when you're working with young people. Very important. (Participant 1)

When it came to building bridging connections across ethnic divisions, and with the broader Australian community, supporting integration into mainstream clubs clearly was seen as having the greatest capacity to make a difference.

Wherever they're playing, they have a chance to integrate with anyone and that's what will make them socially adapt to know how Australian people are, how they can be friends with anyone in Australia. As they're growing up they will have the possibilities of walking in anywhere and they know how to team up with anyone. That's why I want to encourage kids... (Participant 2)

I've worked with refugee communities now for over twenty years and I've seen over that time the benefits not just for their children but also for their families in linking into the community through sport. (Participant 5)

I'm a big believer that if you know someone's story...that racism doesn't exist if you get to know someone.....Even now our under 17 boys-we've got South Sudanese boys, we've got Afghani asylum seekers, we've got Indian and Pakistani boys-we've got a real mixture and often at that age there can be that tendency to you know-but they know each other and they respect each other. (Participant 5)

Some of the participants argued cogently that for sport to promote social inclusion and broader social cohesion, integration into mainstream clubs was vital.

Ultimately you want to take the young person and put them in a club structure so they can develop their inclusion and the parents can get involved as well...it's how they build networks, a sense of belonging, health and academic abilities as well. (Participant 10)

It's obviously some small way of helping to maintain and create some cohesion in our local area. To break down barriers and just for the members of the club, it's going to be great to meet and talk to people from different backgrounds. (Participant 9)

\section{Key Barriers and Facilitators}

Interview participants all discussed barriers for refugeebackground young people joining mainstream clubs and these reflected the same challenges as those identified in the literature. Many of those offering short term or continuing programs for refugee young people acknowledged that opportunities to participate in mainstream clubs would be ideal but felt that this was unlikely to be feasible for many.

If they want to get involved in a team it's hard. It's all those surrounding barriers, getting to training. With basketball it's venues scattered around Melbourne that might not be accessible by public transport. A lot of the parents are single parents....A lot of these people are at home dealing with the other six or seven they've got at home. (Participant 4)

It would be perfect if there was a [local soccer] club. Because that would be at the end of their list [of goals] to be registered in a club but because there's no club we can't have that as a goal...so that's a shame because that's what they want. (Participant 1)

Lack of knowledge of systems, gender norms, and competing family priorities-with parents preferring their children to focus on education-were all mentioned; but costs and, to a lesser extent, transport were seen as the key barriers to participation. 
You're talking \$500 memberships [for soccer] and it's things like that. And having to travel halfway across the state to play a game on a Sunday and all those sorts of things. It's not accessible. (Participant 5)

I think finance is an issue. How we're going to do something that's sustainable. As I said, joining the club is expensive. How are we going to fund the players that want to play that aren't able to? So there's a whole lot of questions there. Whether we can do it with our own internal fundraising or apply to various other organisations. So that will be one of the challenges. Then obviously transport. (Participant 9)

Most of the continuing and short term programs for refugee-background children and youth were designed in response to these barriers and were provided free of charge. They also generally countered the transport barrier by being provided where children and young people lived or were attending school. However interviewees involved in providing these programs almost universally regarded the challenge of finding and continually needing to apply for funding a major barrier to sustainability. An additional concern with respect to sustainability was that many of the activities relied on the vision and drive of a single person, without whom it was feared many would 'fall over'.

The experiences of the interviewee who was both an assistant school principal and a cricket coach made him a particularly strong advocate.

I just think that if we're really serious about trying to cut down on crime and trying to cut down on drug abuse. The research is there....If kids are playing sport they won't get involved in those things. And particularly from low socio-economic groups....[Those kids] don't have access to sport and they will get involved in those harmful activities. I just think that there's got to be some sort of way I think in a country like Australia, where we can provide families with an opportunity for their kids to be able to access sport for free. (Participant 5)

Integrating young people successfully into mainstream clubs was in each case dependent on having someone associated with the club making the effort to reach out to families and assist with communications and transport. In two cases, people who were themselves from refugeebackground communities were employed specifically in community liaison roles and this model was reported to be an extremely effective way of engaging and supporting young people to participate. In case 1 , a club had secured sponsorship in order to waive membership fees and then:

[We employed] two (what we call) multicultural sports aides or MSAs for short.... guess to be able to communicate information, build trust and also to help provide much needed support with transport....We've had a couple of other clubs replicate it on a smaller scale and it seems to be working quite successfully for them as well. (Participant 5)

In case 2, a Multicultural Liaison Officer (Participant 2) was paid on a part-time basis by the local council to perform a similar role. He described how he helped to organise transport, met with parents to explain the benefits of their children being involved in sport and provided a communication link between coaches and young people, helping to educate the latter about the importance of regular and punctual attendance at training and games as well as expectations about behaviour.

Other interview participants also spoke about the value of having someone in that type of role if trying to integrate young people into mainstream clubs.

You could potentially have people who are champions within those clubs to allow the [right] environment to exist....Because otherwise, it's good luck-go to a club, turn up to training, it's just a normal football training session and it can be a bit daunting I guess. (Participant 6)

That go-between. Because the whole system of okay, here's the tryouts, giving that information out to parents. It just doesn't work. So you need an intermediary to go between. (Participant 4)

Other key facilitators of successful participation discussed by virtually all participants were the need for flexibility around what was offered and the value of partnerships between different organisations offering services to this population group. Two of those interviewed also recounted instances where refugee-background young people had faced overt racism in mainstream sports settings and stressed the importance of developing improved systems and responses to such incidents.

\section{Capacity of Sports Participation to Promote Social Inclusion}

Interviewees representing each of the participation models spoke about their programs promoting integration and inclusion. For all models, sport was seen as a means of helping young people to understand and participate in Australian culture; a way of benefiting health, wellbeing, self-esteem and confidence; and as an activity that contributed to behavioural attributes supporting education. The opportunity to experience success and reward for effort-otherwise not available to those whose educational background meant they struggled in the classroom-was seen as particularly valuable (Block, Cross, Riggs, \& Gibbs, 2014). All models were also viewed as fostering bonding and linking social connections. Thus, in terms of Ager and Strang's (2008) conceptual framework, even those participation models that stopped 
short of integration into mainstream may have substantial potential to promote inclusion by supporting health, education, and bonding and linking connections.

Integrating refugee-background young people into mainstream clubs had the additional capacity to directly support development of bridging social connections likely to be particularly critical for promoting inclusion. While bonding social capital is essential for wellbeing, bonding ties are also responsible for creating social boundaries. The development of group identity and social capital within groups is, by its nature, exclusionary with respect to those with different norms and identities. This raises difficulties for attempts to couple this type of social capital with social inclusion (Eriksson, 2011; Field, 2003; Wakefield \& Poland, 2005). Unlike bonding networks, bridging networks are invariably depicted as positive for collective wellbeing (Narayan, 1999). Connections across social boundaries have also been characterised as providing instrumental returns to individuals. They are useful for obtaining new knowledge and resources (economic, political and social) not already possessed by an individual or group (Portes, 1998). Linking social capital, refers particularly to relationships between individuals and institutions. It implies a capacity to leverage resources, ideas and information from institutions and agencies and is regarded as particularly important for marginalised individuals and communities (Domínguez \& Arford, 2010; Warr, 2005). Thus, an optimal balance between bonding, bridging and linking social connections is likely to be most effective in facilitating inclusion and wellbeing (Szreter, 2002) and also for supporting those domains labelled facilitators of inclusion: language, cultural knowledge, and a sense of safety and stability.

Models which employed bicultural workers were not only the most successful at integrating young people into mainstream clubs but also provided an important avenue for communicating with parents and family members. Couch (2007) has suggested that involving families and the wider communtiy is crucial for developing effective participation strategies for refugee-background young people to ensure their support. Failure to do this risks straining family bonds as well as the sustainability of participation.

\section{Conclusions}

Findings from this research indicate that the three identified participation models were all perceived as having significant benefits for refugee-background young people. While each of the models has the capacity to support a number of domains of inclusion, integration into mainstream clubs has the additional capacity to promote the development of bridging social capital with consequent greater potential impact. Both short-term and ongoing programs specifically for refugee youth were clearly valued but it was reported by many of the participants that facilitating integration into clubs remained the ideal.
Although barriers to implementing this model successfully were substantial, key facilitators emerged. These included fee subsidies and having someone who actively linked young people and their families into clubs, assisting with communication and transport. Given that this outreach role appeared to be a critical ingredient of successful integration into clubs, a key recommendation is that sporting associations and governments fund and evaluate participation models employing bicultural workers in community liaison roles with a view to expanding this practice.

This study suggests that drawing on a theoretically informed model of integration can assist with analysing the relative benefits of differing sports participation models and with designing future interventions. The study also has a number of limitations. The sample included only service providers and its size was small-although analyses suggested that data saturation was reached for this category of participants. Additional research is clearly needed to investigate the experiences of refugeebackground young people and their families themselves; and to assess the impacts of sports participation interventions on outcomes associated with social inclusion.

\section{Acknowledgements}

This research was funded by a generous donation from Marie Kinsella and David Conolly. The authors gratefully acknowledge the generosity of the research participants in sharing their time and experiences. The late Professor Elizabeth Waters is also warmly remembered for her role in supporting this study.

\section{Conflict of Interests}

The authors declare no conflict of interests.

\section{References}

Ager, A., \& Strang, A. (2008). Understanding integration: A conceptual framework. Journal of Refugee Studies, 21(2), 166-191.

Australian Department of Immigration and Border Protection. (2017). Humanitarian programme statistics. Retrieved from https://www.border.gov.au/about/ reports-publications/research-statistics/statistics/live -in-australia/humanitarian-programme

Beirens, H., Hughes, N., Hek, R., \& Spicer, N. (2007). Preventing social exclusion of refugee and asylum seeking children: Building new networks. Social Policy and Society, 6(2), 219-229.

Block, K., Cross, S., Riggs, E., \& Gibbs, L. (2014). Supporting schools to create an inclusive environment for refugee students. International Journal of Inclusive Education, 18(12), 1337-1355.

Bourdieu, P. (1986). The forms of capital. In J. Richardson (Ed.), Handbook of theory and research for the sociology of education. New York: Greenwood Press. 
Caperchione, C. M., Kolt, G. S., \& Mummery, W. K. (2009). Physical activity in culturally and linguistically diverse migrant groups to Western society: A review of barriers, enablers and experiences. Sports Medicine, 39(3), 167-177.

Charmaz, K. (2003). Qualitative interviewing and grounded theory analysis. In J. F. Gubrium \& A. H. Holstein (Eds.), Handbook of interview research (pp. 675-694). Thousand Oaks: Sage

Cheong, P. H., Edwards, R., Goulbourne, H., \& Solomos, J. (2007). Immigration, social cohesion and social capital: A critical review. Critical Social Policy, 27(1), 24-49.

CMY. (2016). Information sheet: Youth arrivals to Victoria. Melbourne: Centre for Multicultural Youth.

Coalter, F. (2007). Sports clubs, social capital and social regeneration: 'Ill-defined interventions with hard to follow outcomes'? Sport in Society, 10(4), 537-559.

Coalter, F. (2015). Sport-for-change: Some thoughts from a sceptic. Social Inclusion, 3(3), 19-23.

Couch, J. (2007). Mind the gap: Considering the participation of refugee young people. Youth Studies Australia, 26(4), 37.

Domínguez, S., \& Arford, T. (2010). It is all about who you know: Social capital and health in low-income communities. Health Sociology Review, 19(1), 114-129.

Eime, R. M., Young, J. A., Harvey, J. T., Charity, M. J., \& Payne, W. R. (2013). A systematic review of the psychological and social benefits of participation in sport for children and adolescents: Informing development of a conceptual model of health through sport. International Journal of Behavioral Nutrition and Physical Activity, 10(98).

Eriksson, M. (2011). Social capital and health: Implications for health promotion. Global Health Action, 4, 5611-5621.

Field, J. (2003). Social capital. New York: Routledge.

Hardwick, S. W. (2003). Migration, embedded networks and social capital: Towards theorising North American ethnic geography. International Journal of Population Geography, 9(2), 163-179.

Hawe, P., \& Shiell, A. (2000). Social capital and health promotion: A review. Social Science \& Medicine, 51(6), 871-885.

Hoye, R., Nicholson, M., \& Brown, K. (2015). Involvement in sport and social connectedness. International Review for the Sociology of Sport, 50(1), 3-21.

Kay, T. (2009). Developing through sport: Evidencing sport impacts on young people. Sport in Society, 12(9), 1177-1191.

Kelly, L. (2011). 'Social inclusion' through sports-based interventions? Critical Social Policy, 31(1), 126-150.

Korac, M. (2003). Integration and how we facilitate it: A comparative study of the settlement experiences of refugees in Italy and the Netherlands. Sociology, $37(1), 51$.
Narayan, D. (1999). Bonds and bridges: Social capital and poverty (Vol. 2167). World Bank Publications.

O’Driscoll, T., Banting, L. K., Borkoles, E., Eime, R., \& Polman, R. (2013). A systematic literature review of sport and physical activity participation in Culturally and Linguistically Diverse (CALD) migrant populations. Journal of Immigrant and Minority Health, 1-16.

Olliff, L. (2007). Playing for the future: The role of sport and recreation in supporting young people to 'settle well' in Australia. Melbourne: Centre for Multicultural Youth Issues.

Portes, A. (1998). Social capital: Its origins and applications in modern sociology. Annual Review of Sociology, 24(1), 1-22.

Putnam, R. D. (2000). Bowling alone: The collapse and revival of American community. New York: Simon \& Schuster.

QSR International. (2015). NVivo qualitative data analysis software; Version 11. Melbourne.

Refugee Council of Australia. (2010). A bridge to a new culture: Promoting the participation of refugees in sporting activities. Sydney: Refugee Council of Australia.

Rosso, E. G., \& McGrath, R. (2013). Beyond recreation: Personal social networks and social capital in the transition of young players from recreational football to formal football clubs. International Review for the Sociology of Sport, 48(4), 453-470.

SCOA. (August 2012). Discussion paper-Sports and settlement. Sydney: Settlement Council of Australia.

Spaaij, R. (2012). Beyond the playing field: Experiences of sport, social capital, and integration among Somalis in Australia. Ethnic and Racial Studies, 35(9), 1519-1538.

Spaaij, R. (2013). Cultural diversity in community sport: An ethnographic inquiry of Somali Australians' experiences. Sport Management Review, 16, 29-40.

Spaaij, R., Farquharson, K., \& Marjoribanks, T. (2015). Sport and social inequalities. Sociology Compass, 9(5), 400-411.

Szreter, S. (2002). The state of social capital: Bringing back in power, politics, and history. Theory and Society, 31(5), 573-621.

Vermeulen, J., \& Verweel, P. (2009). Participation in sport: Bonding and bridging as identity work. Sport in Society, 12(9), 1206-1219.

Wakefield, S. E. L., \& Poland, B. (2005). Family, friend or foe? Critical reflections on the relevance and role of social capital in health promotion and community development. Social Science \& Medicine, 60(12), 2819-2832.

Warr, D. (2005). Social networks in a 'discredited' neighbourhood. Journal of Sociology, 41(3), 285-308.

Woolcock, M. (2001). The place of social capital in understanding social and economic outcomes. Canadian Journal of Policy Research, 2(1), 11-17. 


\section{About the Authors}

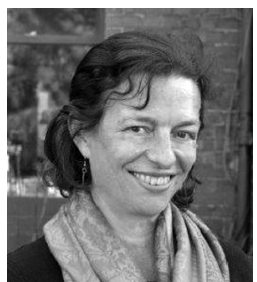

Karen Block is a Research Fellow in the Jack Brockhoff Child Health and Wellbeing Program in the Centre for Health Equity, Melbourne School of Population and Global Health. Her research focuses on social determinants of health inequalities and wellbeing. She has a particular interest in building a deeper understanding of the issues impacting on social inclusion for immigrant and refugee-background children and families in Australia and aims to inform policy and program development for this population group.

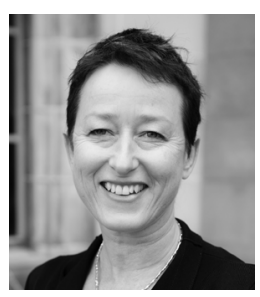

Lisa Gibbs is Associate Professor and Director of the Jack Brockhoff Child Health and Wellbeing Program in the Centre for Health Equity, and Co-Chair of the Children's Lives Research Initiative at the University of Melbourne. She explores sociocultural and environmental influences on health and wellbeing to develop solutions and enhance opportunities for children and young people to thrive. 